\title{
Non Hodgkin's lymphoma with cutaneous involvement in AIDS patients. Report of five cases and review of the literature
}

\section{ABSTRACT}

Cutaneous B cell lymphoma (CBCL) is a lymphoproliferative disorder of neoplastic B cell of the skin with a wide range of clinical manifestations. Commonly, the clinical features of CBCL are plaques, nodules, or ulcerative lesions. Skin is one of the common sites for extra-nodal lymphomas in patients with AIDS and B cell type is less common than T cell type. Only recently, the existence of B cell lymphomas presenting clinically in the skin without evidence of extra-cutaneous involvement has been accepted as primary CBCL. Here, we are presenting 5 patients with cutaneous involvement in the setting of HIV/AIDS disease. Two of them were primary cutaneous nonHodgkin lymphomas. All were CBCL; 3 were immunoblastic, 1 was plasmablastic, and the other was a Burkitt lymphoma. We analyzed the epidemiological, clinical, virological, and immunological characteristics of this group of patients.

Keywords: AIDS, HIV, cutaneous lymphoma.

[Braz J Infect Dis 2010;14(1):81-85] @Elsevier Editora Ltda.
Authors

Marcelo Corti ${ }^{1}$

Luis De Carolis

Rubén Solari ${ }^{1}$

María F. Villafañe ${ }^{1}$

Ricardo Schtirbu ${ }^{2}$

Daniel Lewi ${ }^{3}$

Marina Narbaitz ${ }^{4}$

${ }^{1}$ HIV/AIDS Division and

${ }^{2}$ Histopathology

Laboratory, Infectious

Diseases F. J. Muñiz

Hospital;

${ }^{3}$ Oncology Section, General

Acute Hospital J. A.

Fernández;

${ }^{4}$ Histopathology

Laboratory, National

Academy of Medicine;

Buenos Aires, Argentina.

\section{INTRODUCTION}

Non-Hodgkin's lymphomas (NHL) are frequent malignancies in AIDS patients. The estimated related risk of NHL associated with HIV infection is 100 times greater than in general population, and the risk increases with the progressive immunosuppression related with retrovirus. ${ }^{1-4}$ More than 90\% of HIV-associated NHL is derived from $\mathrm{B}$ cells and the majority is high grade. Extranodal presentation is most frequent in HIV-seropositive patients than in general population and occurs in $70 \%$ to $80 \%$ of the cases. Cutaneous B cell lymphoma is an infrequent group of neoplasms that according to the World Health Organization (WHO) and the European Organization for Research and Treatment of Cancer (EORTC) classification, ${ }^{5}$ form a specific group of non Hodgkin's lymphoma (NHL). Primary cutaneous B-cell lymphomas are a heterogeneous group of B-cell extranodal lymphomas arising in the skin, without evidence of extracutaneous disease at the time of diagno- sis. ${ }^{6}$ In some cases they represent the initial manifestation of a systemic lymphoma.

The aim of this study was to present the epidemiological, clinical, histopathological, immunological, and virological findings in five patients with HIV/AIDS disease and NHL with cutaneous involvement.

\section{CASE REPORTS}

We analyzed retrospectively all cases of lymphomas with cutaneous involvement occurring in human immunodeficiency virus (HIV) infected patients from the files of the HIV/AIDS Division of the Infectious Diseases "Francisco J. Muñiz" Hospital in Argentina, during the years 2005 and 2006. Diagnosis of cutaneous NHL was made by biopsy of skin lesions and histopathological examination.

We defined NHL and B symptoms by the Ann Arbor staging system. ${ }^{2}$ Immunostaining with monoclonal antibodies was performed in all biopsy smears to determine the immunophenotype of the lymphoma.
Submitted on: 08/15/2009 Approved on: 10/10/2009

Correspondence to: Marcelo Corti Division of HIV/AIDS disease

Puán $381,2^{\circ}$ piso, C1406CQG

Buenos Aires, Argentina. E-mail: marcelocorti@ fibertel.com.ar

We declare no conflict of interest. 
The clinical staining procedure included: bone marrow biopsies in four patients and total body computed tomography (CT) scan (brain, thorax, abdomen, and pelvis) which was performed in all patients.

The Epstein-Barr virus (EBV) genome in tumour cells was detected by immunohistochemistry (IHQ) tests for the latent membrane protein type 1 (LMP-1) and by in situ hybridization (ISH) for the EBERs. Polymerase chain reaction was performed for detection of human herpesvirus-8 (HHV-8) DNA in patient with AIDS related plasmablastic lymphoma.

During the period 2005 to 2006 there were 3,556 admissions in the HIV/AIDS division of our hospital. Forty three patients $(1.2 \%)$ had diagnosis of AIDS related lymphomas; 5 of them (11.6\%) initially presented with cutaneous compromise. All of them were males; median
Figure 1. Multiple and nodular cutaneous lesions in a patient with Burkitt's lymphoma.

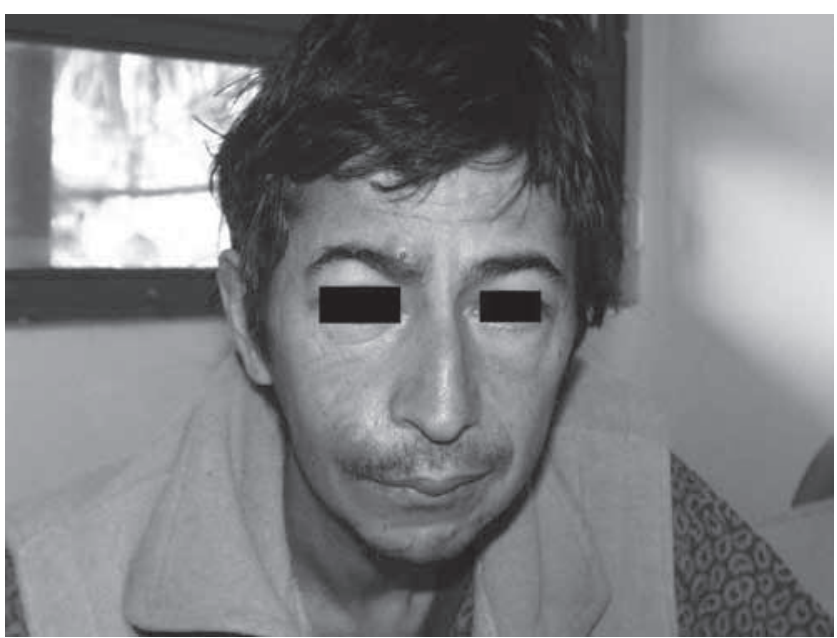

Table 1. Main clinical findings in patients with lymphomas and skin involvement

\begin{tabular}{|c|c|c|c|c|c|}
\hline & Patient 1 & Patient 2 & Patient 3 & Patient 4 & Patient 5 \\
\hline Sex & Male & Male & Male & Male & Male \\
\hline Age (years) & 44 & 42 & 34 & 34 & 36 \\
\hline $\begin{array}{l}\text { Risk factor for } \\
\text { HIV infection }\end{array}$ & $\begin{array}{l}\text { Intravenous } \\
\text { drug user (IDU) }\end{array}$ & Homosexual & Heterosexual & Bisexual & IDU \\
\hline Localization & $\begin{array}{l}\text { Systemic with } \\
\text { facial cutaneous } \\
\text { lesions }\end{array}$ & $\begin{array}{l}\text { Single perianal } \\
\text { cutaneous (chest } \\
\text { wall and scalp) }\end{array}$ & $\begin{array}{l}\text { Initiall } \\
\text { cutaneous } \\
\text { lesion }\end{array}$ & $\begin{array}{l}\text { Single perianal } \\
\text { cutaneous } \\
\text { lesion }\end{array}$ & $\begin{array}{l}\text { Disseminated } \\
\text { cutaneous } \\
\text { lesions }\end{array}$ \\
\hline $\begin{array}{l}\text { Bone marrow } \\
\text { infiltration }\end{array}$ & NR & Negative & Positive & Negative & Negative \\
\hline $\begin{array}{l}\text { Brain, thorax, } \\
\text { abdomen and } \\
\text { pelvis CT scans }\end{array}$ & Liver compromise & Normal & $\begin{array}{l}\text { Costal and cranial } \\
\text { compromise }\end{array}$ & Normal & $\begin{array}{l}\text { Costal and } \\
\text { neighbour } \\
\text { pulmonary } \\
\text { parenchymal } \\
\text { involvement }\end{array}$ \\
\hline $\mathrm{HCV}$ & Positive & Negative & Negative & Negative & Positive \\
\hline CD4 (cells / $\mathrm{LL}$ ) & 78 & 48 & 153 & 54 & 56 \\
\hline Phenotype & B & B & B & B & B \\
\hline Histological Subtype & Burkitt & Immunoblastic & Immunoblastic & Immunoblastic & Plasmablastic \\
\hline EBV & Negative & NR & Negative & $\begin{array}{l}\text { Positive } \\
\text { (HHV-8+) }\end{array}$ & Positive \\
\hline Treatment & No & HAART alone & No & $\begin{array}{l}\text { Chemotherapy } \\
\text { plus HAART }\end{array}$ & $\begin{array}{l}\text { Chemotherapy } \\
\text { plus HAART }\end{array}$ \\
\hline Survival & 20 days & 24 months & 16 days & 18 months & 6 months \\
\hline
\end{tabular}

15. NR: not realized 
Figure 2. A large tumoral lesion on the right shoulder corresponding to the diagnosis of plasmablastic lymphoma..

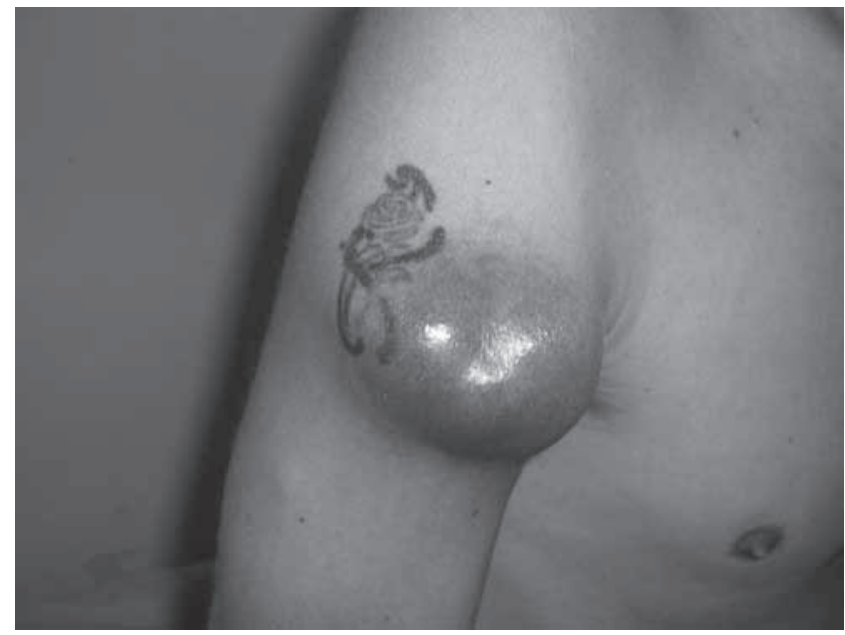

Figure 4. Atypical lymphoid infiltrate with large and multinucleated cells with little or unapparent cytoplasm, the majority containing several and small nucleoli. Between the atypical elements we can see reactive histiocites situated within clear spaces, with "starred sky" aspect. The mitotic index was high with numerous cellular rests of picnotic nuclei, indicating the great cellular spare of this tumour. The histopathological diagnosis was Burkitt's lymphoma..

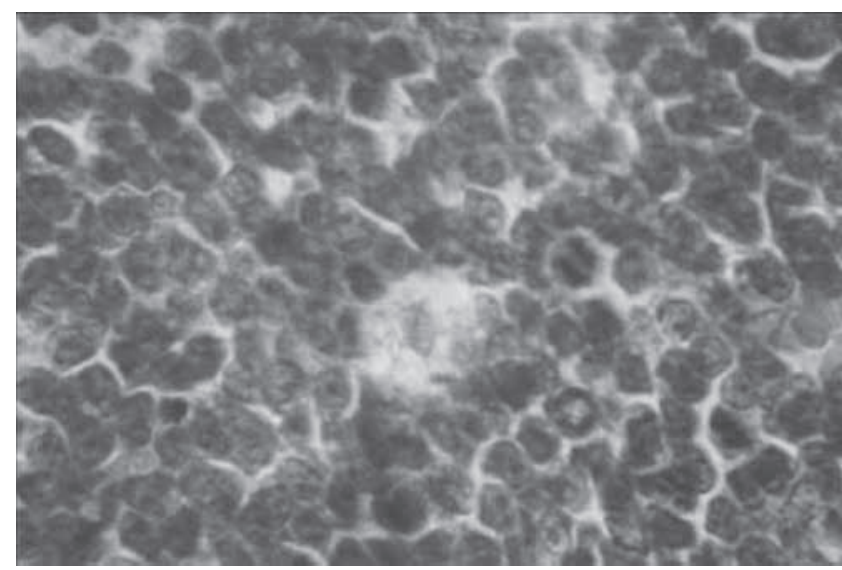

age was 36 years. All patients presented with B symptoms and nodular and/or tumours lesions with different cutaneous locations (Figure 1, 2 and 3). In two patients, lymphoma was the first AIDS-defining illness. Extracutaneous involvement was confirmed by biopsy in three patients $(60 \%)$. The other two were classified as primary cutaneous lymphomas (patients 2 and 4). Median count of CD4+ T-cell at the time of neoplasm diagnosis was 56 cells $/ \mu \mathrm{L}$. All lymphomas were extranodal and of high grade and B phenotype. Three of them were immunoblastic, one plasmablastic, and one Burkitt lymphoma
Figure 3. Multiple and reddish tumoral lesions on chest wall in a patient with plasmablastic lymphoma with cutaneous involvement.

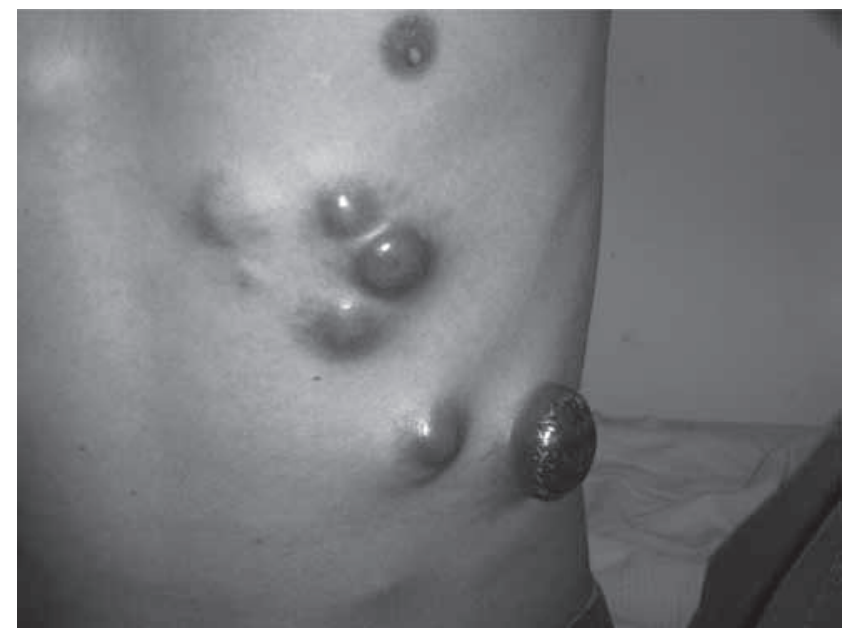

(Figure 4). The EBV genome in the atypical cells was detected in 2 patients (one with immunoblastic and the other with plasmablastic lymphoma). The HHV-8 genome was also detected in the patient with plasmablastic lymphoma. Two patients could not receive chemotherapy due to rapid progression of illness or presence of other opportunistic diseases. One patient with perianal cutaneous lymphoma received antiretroviral treatment (ART) only. The other two were treated with ART plus chemotherapy based on CHOP (cyclofosfamide, doxorubicin, vincristine, and prednisone) completion of six cycles. The patient with plasmablastic lymphoma died after 6 months of being diagnosed with neoplasm. The other two are still alive with a complete remission of neoplasm disease, after 18 and 24 months, respectively. The main clinical features are summarised in Table 1.

\section{DISCUSSION}

Patients infected with HIV are at increased risk of developing NHL, including primary central nervous system lymphoma (PCNSL). Their frequency and clinical aggressive presentation has led to consider them as a criterion for stage C of AIDS, according to the Centers for Disease Control (CDC) and prevention classification. AIDS-related NHL (AIDS-NHLs) are mostly, but not all, of high-grade and $B$ phenotype, as in the series we presented. ${ }^{7}$ Cutaneous lymphomas are characterized by an initial accumulation of mononuclear, mostly lymphocytic cells in the skin. ${ }^{8}$ 
Primary cutaneous lymphomas represent 5\% to $10 \%$ of total extranodal NHL and are the second in frequency after lymphomas arising gastrointestinal tract. ${ }^{9}$ Cutaneous B-cell lymphomas are less frequent than primary cutaneous T-cell and include about $20 \%$ to $25 \%$ of all primary cutaneous lymphomas. ${ }^{5}$ They include subtypes with an indolent course and evolution; and others, as the primary diffuse large B-cell lymphoma (DLBCL), more aggressive. DLBCL are divided in two subcategories, including the centroblastic and the immunoblastic lymphomas of the previous Kiel classification. ${ }^{9}$ In the serie of Beylot-Barry et al. that included 21 cases of cutaneous lymphomas, the $10 \mathrm{~B}$-cell cutaneous lymphomas were immunoblastic or centroblastic lymphomas. Four of them expressed the EBV genome. ${ }^{10}$ In our series, DLBCL subtype immunoblastic include three of the five cases $(60 \%)$ with one plasmablastic and one Burkitt lymphoma.

Clinical presentation of cutaneous NHL includes single or multiple subcutaneous nodes, dermis papules, and ulcerative and infiltrative lesions. Specific cutaneous lesions are more frequents in NHL in comparison with the Hodgkin disease (HD). Patients with NHL showed cutaneous involvement in $15 \%$ to $20 \%$ of cases and in $5 \%$ to $10 \%$ of them, skin lesions are the first manifestation of the disease. In contrast, only $5 \%$ to $10 \%$ of patients with HD present cutaneous lesions. ${ }^{5,9,10}$

Cutaneous compromise in NHL is an expression of advanced neoplasm disease. The five patients of our series had diagnosis of advanced HIV/AIDS disease with severe immunosuppression and low CD4 T - cell counts at the time of neoplasm diagnosis. ${ }^{10}$

EBV appears to play a major role in certain AIDSNHL, such as AIDS-related DLBCL, including PCNSL and AIDS anaplastic NHL. EBV is strongly associated with the pathogenesis of these subtypes of lymphomas. The recently identified HHV-8 is related with the pathogenesis of AIDS-primary effusion lymphoma and oral plasmablastic lymphoma. ${ }^{11,12} \mathrm{EBV}$ could be identified by ISH and IHQ in 2 patients of this series; in one of them also with HHV-8 (plasmablastic lymphoma).

The number of lesions, single versus multiple, is a prognostic factor in primary cutaneous B-cell lymphomas. ${ }^{13}$ In this series, the patients with single perianal skin lesions had a significant better survival as there was no evidence of disseminated disease (in spite of the coexistence of another neoplasm, Kaposi's sarcoma, in one of them) after 18 and 24 months of the diagnosis. The therapy was based on six cycles of chemotherapy followed by HAART in one of them and HAART alone in the other, respectively.
In conclusion, lymphomas with cutaneous compromise are uncommon in HIV-infected patients. The most important diagnosis elucidation is to determine whether the cutaneous tumour is a primary cutaneous lymphoma or when it represents cutaneous metastases of an aggressive systemic AIDS-related NHL. ${ }^{14}$

In our experience, early diagnosis followed by specific therapy based on highly active antiretroviral therapy (HAART) plus chemotherapy improves the prognosis and the survival of patients with AIDS and cutaneous compromise by NHL.

\section{REFERENCES}

1. Weisenburger DD. Epidemiology of non-Hodgkin's lymphoma. Recent findings regarding an emerging epidemic. Ann Oncol 1994; S19-S24.

2. Corti M, Villafañe MF, Souto L et al. Burkitt's lymphoma of the duodenum in a patient with AIDS. Rev Soc Bras Med Trop. 2007; 40:338-40

3. Gandhi MK, Khanna R. Viruses and lymphoma. Pathology 2005; 37:420-3.

4. Corti M, Solari R, Cangelosi D et al. Oral cavity lymphoma as a secondary AIDS-defining neoplasm in a patient on HAART with immune reconstitution. Rev Soc Bras Med Trop 2007; 40:582-4

5. Willemze R, Meijer CJ. EORTC classification for primary cutaneous lymphomas: the best guide to good clinical management. European Organization for Research and Treatment of Cancer. Am J Dermopathol 1999; 21:265-73.

6. Goteri G, Ranaldi R, Simonetti $\mathrm{O}$ et al. Clinicopathological features of primary cutaneous B-cell lymphomas from an academic regional hospital in central Italy: No evidence of Borrelia burgdorferi association. Leukemia \& Lymphoma 2007; 48:2184-88

7. Diamond C, Taylor TH, IM T, Anton-Culver H. Presentation and outcomes of systemic non-Hodgkin's lymphomas: A comparisson between patients with acquired immunodeficiency syndrome (AIDS) treated with highly active antiretroviral therapy and patients without AIDS. Leukemia \& Lymphoma 2006; 47:1822-9.

8. Dummer R, Asagoe K, Cozzio A et al. Recent advances in cutaneous lymphomas. J Dermatol Sci 2007; 48:157-67.

9. Willemze R, Jaffe ES, Burg G et al. WHO-EORTC classification for cutaneous lymphomas. Blood 2005; 105:3768-85.

10. Beylot-Barry M, Vergier B, Masquelier B et al. The spectrum of cutaneous lymphomas in HIV infection: A study of 21 cases. Am J Surg Pathol 1999; 23:1208-16.

11. Camilleri-Broet S, Davi F, Feuillard J et al. High expression of latent membrane protein 1 of Epstein-Barr virus and BCL-2 oncoprotein in acquired immunodeficiency-related primary brain lymphomas. Blood 1995; 86:432-5. 
12. Allen C, Kalmar J, Suster S, Baiocchi R, Nuovo G. Oral plasmablastic lymphomas in AIDS patients are associated with Human Herpesvirus 8. Am J Surg Pathol 2004; 28:41-4.
13. Grange F, Bekkenk MW, Weschsler J et al. Prognostic factors in primary cutaneous large B-cell lymphomas: A European multicenter study. J Clin Oncol 2001; 19:3602-10.

14. Levine AM. Acquired immunodeficiency syndrome-related lymphoma. Blood 1992; 80:8-20. 